\title{
PERANCANGAN DAN PEMBANGUNAN APLIKASI E-COMMERCE BERBASIS WEB UNTUK MENINGKATKAN PENJUALAN PADA TOKO JAKET KULIT NAUFAL
}

\author{
Ahmad Rizki Fadillah ${ }^{1)}$, Lusi Fajarita ${ }^{2)}$ \\ ${ }^{1}$ Sistem Informasi, Fakultas Teknologi Informasi, Universitas Budi Luhur \\ 1,2 Jl. Raya Ciledug, Petukangan Utara, Kebayoran Lama, Jakarta Selatan 12260 \\ E-mail : ahmad.rizki.f1@gmail.com ${ }^{1)}$, lusi.fajarita@budiluhur.ac.id ${ }^{2}{ }^{2}$
}

\begin{abstract}
Abstrak
Electronic Commerce atau E-commerce merupakan suatu konsep yang biasa dilihat sebagai suatu kegiatan transaksi jual beli barang atau jasa pada media internet. Electronic Commerce merupakan kegiatan bisnis yang dijalankan secara elektronik melalui internet atau melalui jalur komunikasi digital. Penelitian ini mengambil studi kasus pada toko Jaket Kulit Naufal adalah usaha yang berkecimpung dalam bidang fashion dengan fokus menjual jaket kulit pria dan wanita. Mekanisme sistem penjualan pada toko Jaket Kulit Naufal masih kurang efektif, sehingga mengharuskan konsumen mesti datang langsung ke toko. Pemasaran produk yang berjalan sekarang masih menggunakan Media sosial. Saat ini, pada pembuatan laporan masih menggunakan cara manual yaitu dengan pembukuan. Hasil dari riset ini ialah membangun website e-commerce dengan metode Content Management System (CMS) yaitu wordpress. Riset ini dengan metode Bussiness Model Canvas (BMC) agar mempermudah dengan bagan elemen apa saja yang dapat membantu toko Jaket Kulit Naufal dalam kelangsungan produksi dan penjualannya. Hasil akhir dari riset ini ialah membangun website e-commerce agar memudahkan customer pada saat transaksi tanpa ada batas waktu dan tempat dan serta mempermudah pemilik toko Jaket Kulit Naufal dalam meningkatkan penjualan dan pemasarannya serta mempermudah pemilik toko untuk mencetak laporan yang diinginkan.
\end{abstract}

Kata kunci: E-commerce, Jaket, Wordpress

\section{PENDAHULUAN}

Pengertian Electronic Commerce atau ECommerce[1] adalah sebuah aktivitas kegiatan penyebaran, penjualan, pembelian, pemasaran produk (barang dan jasa), dengan menggunakan jaringan telekomunikasi seperti internet. Electronic Commerce dapat juga diartikan sebagai sebuah aktivitas penggunaan teknologi informasi dan komunikasi pengolah digital dalam menjalankan kegiatan transaksi bisnis untuk menciptakan, mengubah, dan mendefenisikan hubungan antara penjual dan pembeli. Toko Jaket Kulit Naufal merupakan salah satu tempat usaha berjualan jaket kulit. Saat ini, pada sistem yang berjalan sekarang, masih memiliki banyak masalah yang terjadi dikedua belah pihak baik dipihak pemilik ataupun pelanggan. Pada pihak pemilik toko saat ini tidak memiliki media khusus untuk mempromosikan produknya, tidak terjualnya stok yang lama karena tidak tercatat dalam stok barang, tidak adanya laporan stok barang, tidak memiliki laporan penjualan. Berdasarkan masalah yang ada, maka perlu adanya solusi berupa penerapan sebuah aplikasi business to customer berbasis e-commerce sehingga aplikasi ini diharapkan akan dapat membantu pihak Toko Jaket Kulit Naufal untuk mempromosikan produknya, membuat laporan transaksi penjualan, laporan stok barang, sehingga dapat membantu pelanggan yang ingin mendapatkan informasi produk, dan membeli produk tanpa mengharuskan datang langsung ke toko.

\section{PENELITIAN SEBELUMNYA}

Penelitian yang telah dilaksanakan oleh [2] yang berjudul "Pembangunan Sistem Penjualan Online Pada Toko Indah Jaya Furniture Surakarta”. Pada riset penelitian kali ini menjelaskan tentang manfaat pembanguna serta penerapan e-commerce dalam kemajuan perkembangan dunia bisnis, yang merupakan suatu kebutuhan untuk memaksimalkan, meningkatkan serta memenangkan persaingan bisnis dalam memasrkan produk-produk. Toko Indah Jaya furnitur ini ialah salah satu perusahaan swasta yang bergerak di bidang penjualan furnitur perlengkapan alat-alat rumah tangga seperti meja, kursi, tempat tidur lemari dan lain-lain. Toko ini masih sangat memerlukan perluasaan untuk bisnis penjualan produk-produk yang telah disediakan oleh Toko Indah Jaya Furniture. Oleh karena itu Toko Indah Jaya Furnitur ini memliki suatu permasalahan bagaimana caranya untuk memperluas area dalam mendapatkan pelanggan baik di dalam daerah ataupun luar daerah. Untuk memecahkan dan menyelesaikan permasalahan serta mencari solusi di atas Toko Indah Jaya Furnitur ingin membangun 
sebuah sistem penjualan online (e-commerce) untuk mempromosikan produk-produk yang dibuat oleh toko Indah Jaya furnitur. Pada saat ini internet telah berkembang pesat menjadi salah satu infrastruktur komunikasi yang mumpun untuk melakukan kegiatan bisnis dan jangkauan penerimaan yang luas serta tanpa batas, maka internet-pun sering digunakan sebagai sebuah alat atau media alternaif untuk menjalankan suatu usaha maupun bisnis. Selain dari pada digunakan sebagai media infomasi dan komunikasi, internet juga bisa digunakan sebagai proses jual beli produk atau jasa secara online. Dengan keunggulan internet yang dapat melakukan pelayana tanpa batas dan waktu, akses yang mudah dan biaya yang terjangkau serta kemudahan-kemudahan lainnya, membuat semakin banyak pelaku bisnis yang berkecimpung kedalam dunia e-commerce. Dengan dibangunnya sistem penjualan online tersebut para pelaku bisnis atau usaha baik itu perusahaan menengah ke bawah atau perusahan menengah ke atas dapat memanfatkannya sebagai suatu media untuk mempromoskan perusahannya serta produk-produk yang dimilikinya, agar dapat dikenal lebih luas. Dan diharapkan dapat lebih mempermudah konsumen yang akan membeli produk-produk yang di tawarkan oleh pelaku usaha tanpa mesti harus datang ke tempatnya secara langsung.

Penelitian yang telah dilakukan oleh [3] telah melakukan penelitian mengenai peranan ecommerce yang memiliki fungsi untuk media promosi serta penjualan elektronik, untuk mengetahui kendala masalah yang dihadapi dalam merealisasikan e-commerce. Peneliti ini mengangkat judul “Analisis Peran Teknologi Internet Sebagai Media Transaksi E-commerce Untuk Meningkatkan Perkembangan Ekonomi”. Dewasa ini marak sekali online shop yang beredar di tengah kalangan masyarakat Indonesia maupun dunia. Tidak sedikit orang yang memiliki bisnis dibidang online shop ini. Dengan dukungan teknologi yang semakin canggih seperti sekarang ini, pelaku bisnis online shop pun tidak perlu khawatir lagi. Faktanya sosial media adalah alternatif lain bagi para pelaku bisnis tersebut untuk memasarkan produk dan dagangan mereka. Hanya dengan bermodalkan smartphone, semua pelaku bisnis ini bisa lebih leluasa. Kapanpun dan dimanapun, semua dapat terlaksana secara realtime. Tujuan dari penulisan paper atau jurnal ini adalah untuk menganalisa tentang berbagai aspek mengenai ecommerce dan melakukan beberapa pengujian berupa kuisioner kepada masyarakat tentang seberapa besar peran teknologi internet sebagai media transaksi pada ecommerce yang biasa digunakan untuk pembayaran pada Online Shop. Sehingga dapat menunjukkan bahwa ada begitu banyak sisi positif yang dapat dimanfaatkan dari teknologi yang berkembang saai ini. Selain itu, untuk dapat mengetahui serta mengukur seberapa besar peranan penting teknologi Internet sebagai media transaksi usaha online dalam meningkatkan perkembangan ekonomi di Indonesia.

Dari riset yang telah dilakukan oleh[4] dengan sebuah judul "Perancangan dan Implementasi Aplikasi Website T-shirt Ewako Screen Printing Berbasiskan E-commerce”. Kemajuan teknologi saat ini berkembang begitu pesat. Hal ini ditandai dengan semakin berkembang pesatnya teknologi yang menawarkan kemudahan dalam fasilitas yang mendukung manusia, sehingga upaya menyelesaikan pekeerjaan lebih cepat dan tepat. Aktifitas bisnis melalui teknologi internet yang biasa disebut dengan e-commerce telah banyak digunakan di toko-toko kecil sampai perusahaan yang besar. Atas dasar latar belakang tersebut maka akan dirancang dan direalisasikan aplikasi website yang berbasiskan ECommerce yang diharapkan mampu memberikan banyak manfaat bagi toko-toko dan perusahaan untuk memperluas pemasaran dan meningkatkan omset mereka.

\section{METODE PENELITIAN}

Metode penelitian dibawah ini adalah kerangka pemikiran yang berisikan mengenai masalahmasalah yang ada pada penelitian:

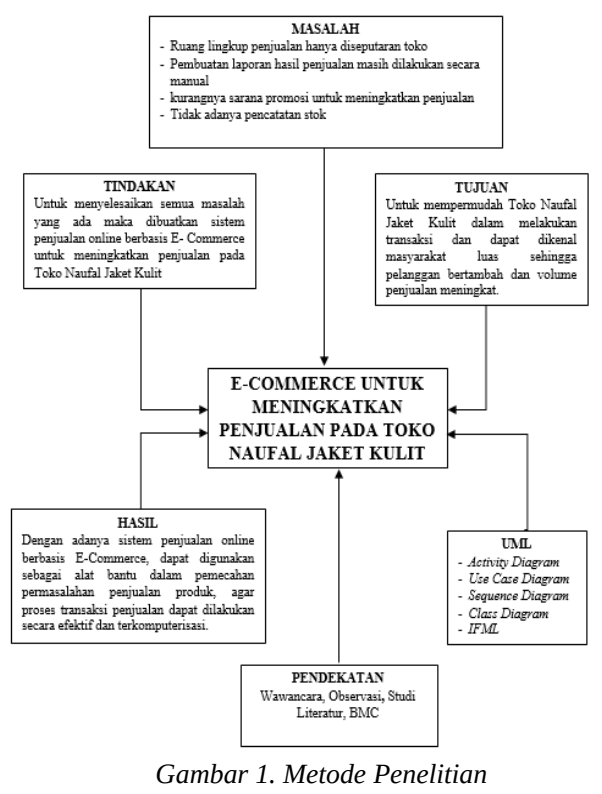

\subsection{Wawancara}

Kegiatan wawancara dilaksanakan untuk mempelajari dan menganalisa sistem yang sedang berjalan sehingga mendapatkan data langsung dari sumbernya disertakan tanya jawab mengenai alur kegiatan dan dokumen pada proses bisnis berjalan. wawancara merupakan suatu percakapan dengan 
tujuan-tujuan tertentu. Pada metode ini peneliti dan responden berhadapan langsung (face to face) untuk memperoleh informasi secara lisan dengan tujuan mendapatkan data yang dapat menjelaskan permasalahan penelitian.

\subsection{Observasi}

Observasi adalah suatu proses pengujian dengan maksud dan tujuan tertentu mengenai sesuatu, khususnya dengan tujuan untuk mengumpulkan data dan fakta. Observasi dilakukan pada Toko Jaket Kulit Naufal.

\subsection{Teknik Dokumentasi}

Teknik dokumentasi ialah cara mengumpulkan data-data melalui dokumen tertulis, seperti arsi-arsip dan buku-buku tentang pendapat, teori atau hukum yang berhubungan dengan masalah penelitian. Hal ini dilakukan untuk mencari data informasi untuk kebutuhan sistem yg akan dibuat.

\subsection{Studi Literatur}

Studi literatur adalah mencari referensi teori yang relefan dengan kasus atau permasalahan yang ditemukan. Tujuannya adalah untuk memperkuat permasalahan serta sebagai dasar teori dalam melakukan studi dan juga menjadi dasar untuk melakukan penelitian.

\subsection{Analisa Sistem}

Analisa sistem ialah salah satu komponen dari suatu sistem informasi ke dalam bagian-bagian komponennya dengan maksud dan tujuan untuk mengidentifkasikan serta mengevaluasi permasalahan, kesempatan, hambatan yang terjadi serta kebutuhan yang diinginkan sehingga dapat dievaluasi, alat yang digunakan ialah Activity Diagram dan Use Case Diagram.

\subsection{Business Model Canvas}

Business Model Canvas merupakan gambaran konseptual dari penelitian ini. Terdapat beberapa bagian elemen dari model konseptual yang dimiliki oleh Toko Jaket Kulit Naufal. Bagian tersebut yaitu yang membedakan mana yang mempengaruhi pemasukan serta pelanggan dan mana yang mempengaruhi proses operasional perusahaan. Terdiri dari 5 bagian elemen yang mempengaruhi pemasukan dan pelanggan yaitu customer segments, value propositions, channels, customer relationships dan revenue stream. Sedangkan terdapat 4 bagian elemen yang mempengaruhi proses operasional dari Toko Jaket Kulit Naufal yaitu key activities, key resources, key partnerships dan cost structures[5].

\subsection{Content Management System (CMS)}

CMS merupakan semacam kumpulan bahasa pemograman yang sudah dikemas menjadi satu perangkat tools yang memudahkan anda dalam pembuatan dan juga pengelolaan sebuah website atau blog [6].

\subsection{Wordpress}

WordPress merupakan sebuah software yang bisa digunakan untuk membuat situs web, baik web pribadi, situs portal berita atau toko online. Di tahun 2003 Matt Mullenweg menemukan WordPress karena kebutuhannya akan sebuah software publishing online. WordPress dibangun dengan menggunakan bahasa pem- rograman PHP dan basis data MySQL yang merupakan perangkat lunak open source. Selain sebagai blog, WordPress juga mulai digunakan sebagai sebuah Content Management System atau CMS karena kemampuannya untuk memodifikasi dan dapat menyesuaiakan dengan kebutuhan penggunanya[7].

\subsection{Search Engine Optimization (SEO)}

SEO ialah strategi pemasaran online yang bertujuan untuk menampilkan dan mengoptimalkan website di halaman pertama hasil pencarian dengan kata kunci pilihan tertentu[8].

\subsection{Woocommerce}

WooCommerce adalah plugin pendukung wordpress, untuk membuat sebuah website $e$ commerce yang dibangun menggunakan flatform wordpress. Semua fitur, kemudahan, kelengkapan termasuk dukungan developernya akan memudahkan dalam pembuatan website e-commerce [9].

\section{HASIL DAN PEMBAHASAN}

4.1. Business Model Canvas (BMC)

Terdapat beberapa bagian elemen dari model konsep yang dimiliki oleh Toko Jaket Kulit Naufal :

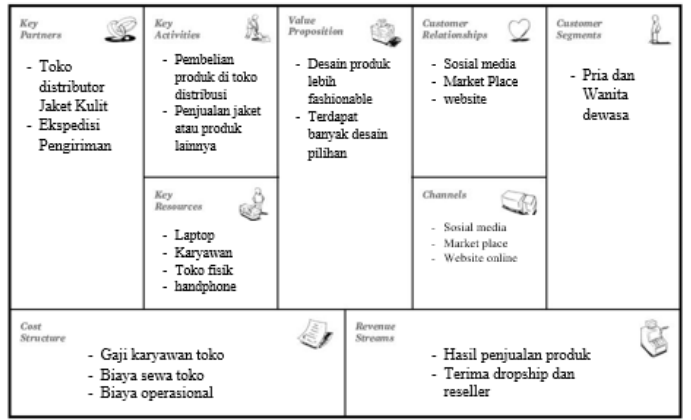

Gambar 2. Business Model Canvas (BMC) 


\subsection{Activity Diagram}

Activity Diagram adalah diagram alur kegiatan yang menjelaskan berbagai macam kegiatan sistem atau pengguna[10]. Berikut ini ialah activity diagram usulan pada toko Jaket Kulit Naufal :

a. Proses Bisnis Usulan Pendaftaran

Customer yang ingin membeli produk diharuskan mengunjungi website. Kemudian, Customer melakukan registrasi untuk pendaftaran member dengan memilih menu my account. Lalu customer mengisi data form regist setelah itu klik tombol register, lalu sistem akan langsung memvalidasi data serta menyimpan data.

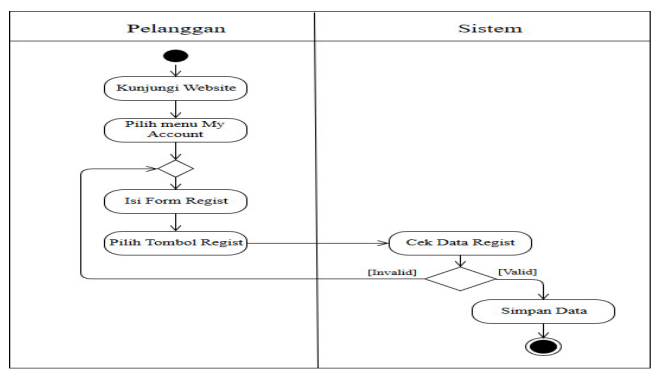

Gambar 3. Activity Diagram Proses Pendaftaran

b. Proses Pemesanan Produk

Setelah berhasil melakukan tahap pendaftaran, Customer kemudian login terlebih dahulu. Lalu Customer bisa memilih produk sesuai dengan kategori yang dipilih, kemudian Customer memilih size serta menentukan jumlah barang yang diinginkan dan klik tombol Add to cart. Jika Customer ingin menambah produk lagi, Customer memilih produk kembali, jika tidak Customer klik tombol View cart untuk checkout. Pada form cart Customer bisa melihat list produk yang telah dibeli, setelah itu Customer memilih tombol Processed to checkout. Pada form checkout Customer mengisi billing details dan melakukan pemilihan ekspedisi pengiriman lalu klik tombol place order. Sistem akan mengirimkan email new order ke admin.

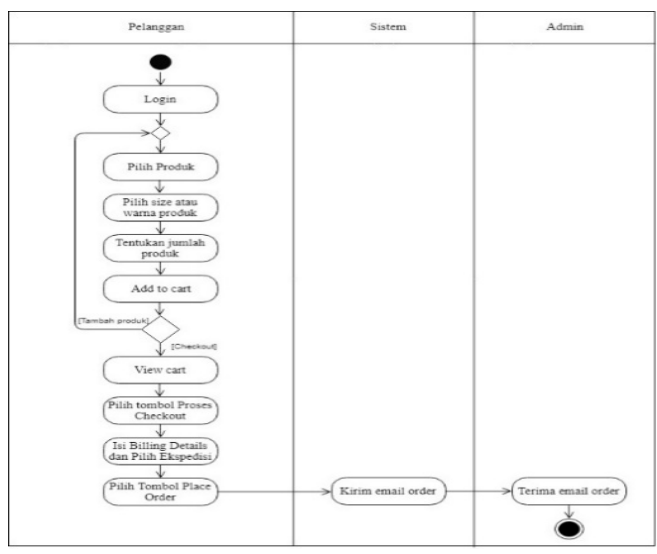

Gambar 4. Activity Diagram Proses Pemesanan Produk c. Proses Pembayaran

Setelah pesanan yang telah dibuat, Customer melakukan transfer pembayaran sesuai dengan jumlah total harga pada order details. Jika telah melakukan transfer pembayaran, Customer melakukan konfirmasi pembayaran dengan pilih menu confirm payment. Lalu Customer mengisi form confirm payment serta mengupload bukti transfer kemudian klik tombol submit. Setelah itu sistem akan mengirim email confirm payment order ke admin.

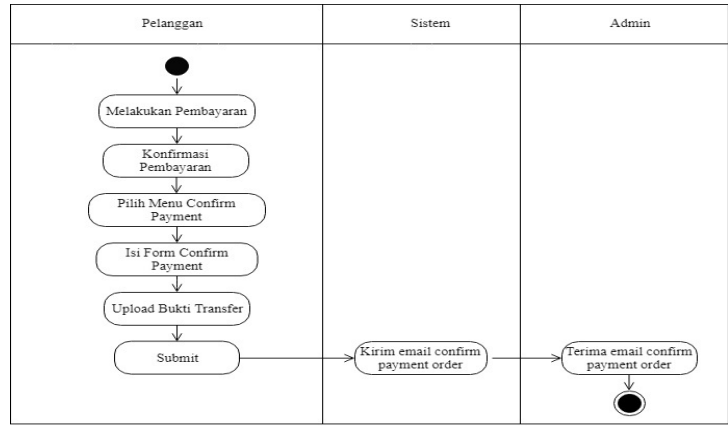

Gambar 5. Activity Diagram Proses Pembayaran

d. Verifikasi Pembayaran

Jika admin telah menerima email confirm payment order, kemudian admin melakukan verifikasi pembayaran dengan klik menu confirm payment setelah itu admin mengecek bukti pembayaran. Jika sesuai admin akan menyetujui pembayaran lalu system akan mengirim email payment order ke pelanggan, jika tidak sesuai maka admin akan langsung mengcancel pembayaran kemudian system akan mengirim email cancelled payment order ke pelanggan.

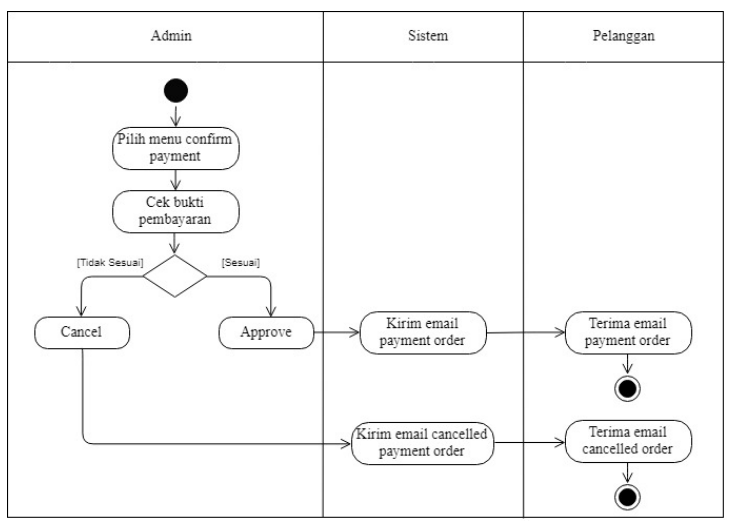

Gambar 6. Activity Diagram Verifikasi Pembayaran

e. Proses Pengiriman

Admin melakukan packing barang untuk dikirim ke jasa pengiriman barang, kemudian admin mendapat resi. Lalu admin menginput resi dengan menggunakan fitur resi pada woocommerce, lalu pilih menu orders, kemudian admin menginput resi 
dan mengklik tombol save tracking. Kemudian admin mengubah status order menjadi delivered lalu mengklik tombol update. Setelah itu sistem akan mengirim email order delivered ke Customer, Kemudian setelah menerima barang yang telah diorder Customer mengklik tombol completed order dimenu orders.

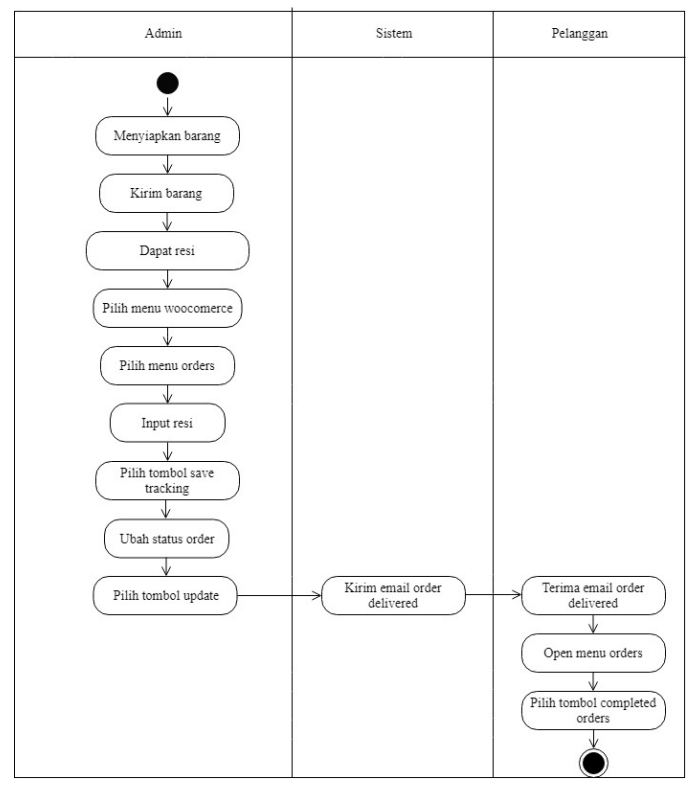

Gambar 7. Activity Diagram Proses Pengiriman

f. Proses Pembuatan Laporan

Setiap bulan admin mencetak laporan penjualan, laporan pemesanan, laporan pembayaran, laporan pengiriman, laporan best seller dan laporan stok yang kemudian akan diserahkan ke pemilik toko.

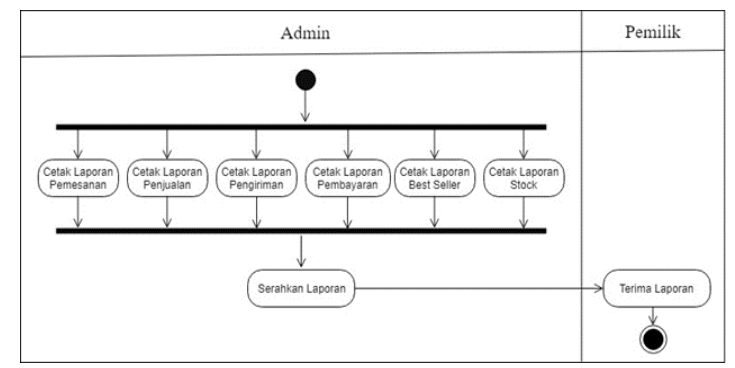

Gambar 8. Activitv Diaaram Proses Pembuatan Laporan

\subsection{Use Case Diagram}

Use Case Diagram ialah penggambaran interaksi antara actor dengan sistem[5]. Berikut inilah Use Case Diagram yang telah dibuat peneliti : a. Use case diagram User

Gambar dibawah ini adalah gambar 9 yaitu merupakan use case diagram user, terdiri dari 2 actor yaitu admin dan pelanggan. Admin dengan pelanggan dapat melakukan aktifitas kegiatan login dan logout untuk mengakses situs web.

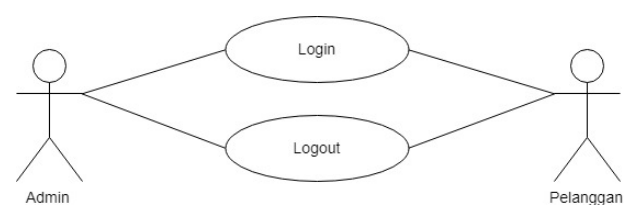

Gambar 9. Use Case Diagram User

b. Use Case Diagram Master

Gambar dibawah ini adalah gambar 10 yang merupakan use case diagram master terdiri dari actor pelanggan dengan actor admin. Actor pelanggan pilih menu my account untuk register. Kemudian di actor admin, jika ingin melakukan aktifitas add new, categories serta attribute ada include yang harus actor pilih terlebih dahulu yaitu menu product.

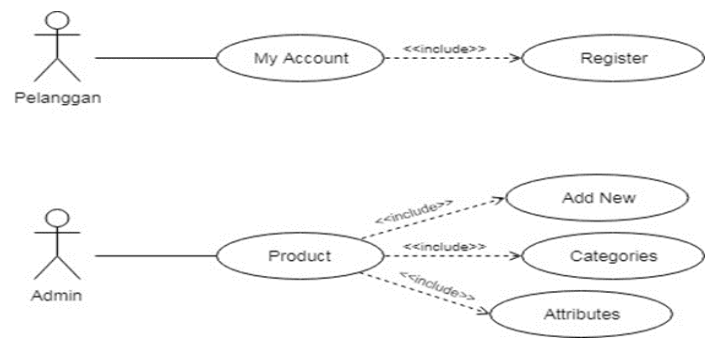

Gambar 10. Use Case Diagram Master

c. Use Case Diagram Transaksi

Gambar dibawah ini adalah gambar 11 merupakan use case diagram transaksi terdiri dari actor pelanggan dengan actor admin. Actor pelanggan akan pilih menu produk, cart, checkout, confirm payment dan wishlist untuk melakukan aktivitas pemesanan produk. Pada actor admin akan pilih menu confirm payment untuk melakukan konfirmasi pembayaran serta pada saat ingin akan melakukan status order dan shipment tracking akan ada include yang harus actor pilih terlebih dahulu yaitu menu order.
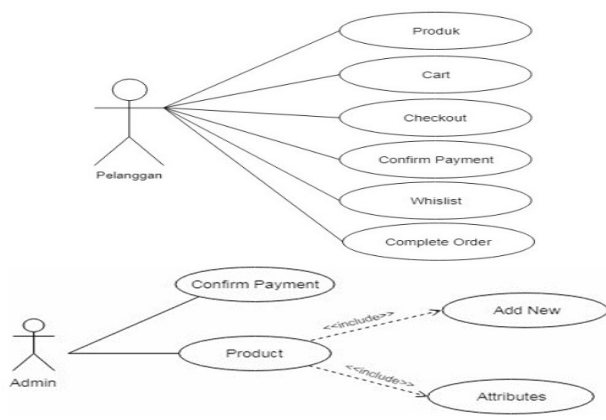

Gambar 11. Use Case Diagram Transaksi

d. Use Case Diagram Laporan

Gambar dibawah ini adalah gambar 12 merupakan use case diagram laporan terdiri dari actor admin dengan actor pemilik. Disini 
mengharuskan admin mencetak laporan penjualan, laporan pemesanan, laporan pembayaran, laporan pengiriman, laporan best seller dan laporan stok.

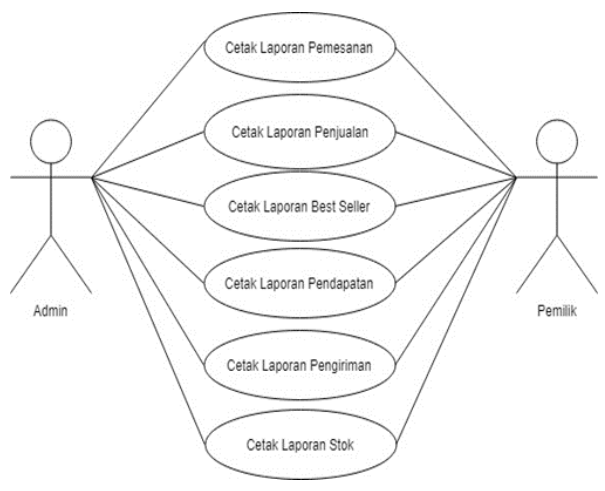

Gambar 12. Use Case Diagram Laporan

\subsection{Rancangan Layar}

a. Rancangan Layar Registrasi dan Login Pelanggan

Gambar 13 merupakan rancangan layar registrasi dan login pelanggan yang dilakukan untuk mengakses website.

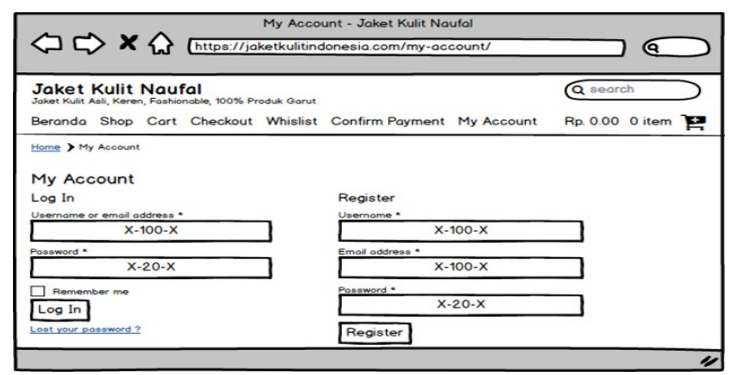

Gambar 13. Rancangan Layar Registrasi dan Login Pelanggan

b. Rancangan Layar Halaman Produk

Gambar 14 merupakan rancangan layar halaman produk pada website Jaket Kulit Naufal.

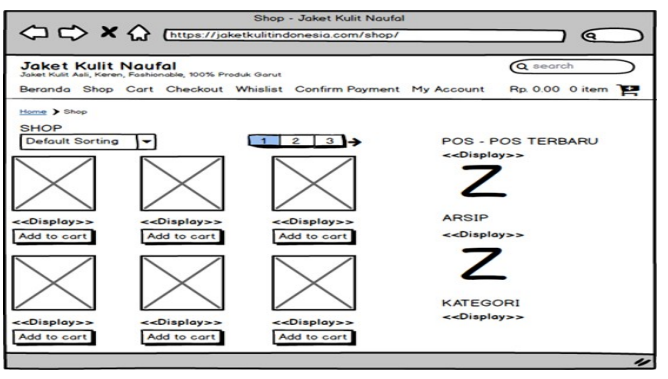

Gambar 14. Rancangan Layar Halaman Produk

c. Rancangan Layar Detil Produk

Gambar 15 merupakan rancangan layar detil produk yang mendeskripsikan details produk.

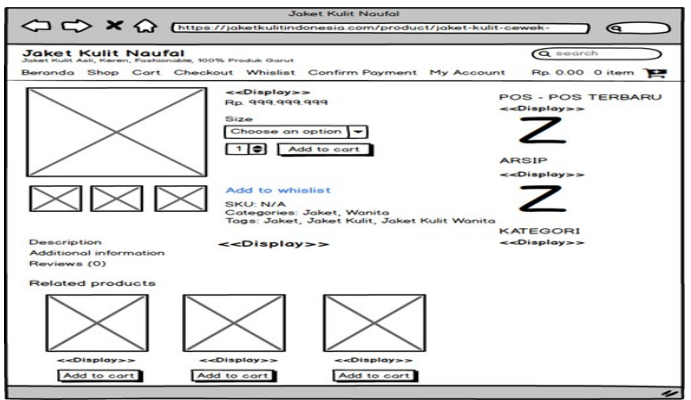

Gambar 15. Rancangan Layar Detil Produk

\subsection{Strategi Search Engine Optimization (SEO)}

SEO ialah strategi pemasaran online yang bertujuan untuk menampilkan dan mengoptimalkan website di halaman pertama hasil pencarian dengan kata kunci pilihan tertentu. Berikut ini adalah strategi SEO yang telah digunakan oleh peneliti dalam penelitian kali ini:

a. Pilih Produk

Pilih salah satu produk yang ingin digunakan untuk strategi seo.

b. Focus Keyphrase

Isi focus keyphrase sesuai dengan focus keyword pencarian. Baiknya kata kunci harus berkaitan dengan nama produk.

c. Edit Snippet

Bagian ini menjelaskan cara menginput SEO title, Slug serta Meta Description yang akan digunakan oleh mesin pencari untuk menentukan Meta Description sudah sesuai deskripsi produk atau halaman situs web yang telah dibuat. Isi dari Meta Description harus menggunakan kalimat yang menggambarkan halaman situs web atau produk yang telah dibuat, menggunakan bahasa yang unik sehingga menghasilkan kata kunci yang unik.

d. Title Gambar Produk

Gambar pada produk adalah suatu hal yang sangat penting untuk meningkatkan keberadaan situs dihalaman pertama pada mesin pencari. Langkah pertamanya ialah pilih gambar produk yang memiliki kapasitas rendah untuk memudahkan mesin pencari untuk memuatnya, kemudian memberikan nama pada gambar produk harus sesuai dengan nama produk yang akan menjadi suatu kata kunci gambar produk pada mesin pencari.

e. Google Search Console

Pada tahap ini akan menjelaskan cara untuk mengindex salah satu halaman produk dengan cara menggunakan Google Search Console.

\section{KELUARAN SISTEM USULAN}

Gambar dibawah ini adalah gambar 17 yang merupakan Sistem usulan keluaran email order yang 
akan diterima pelanggan setelah proses checkout.

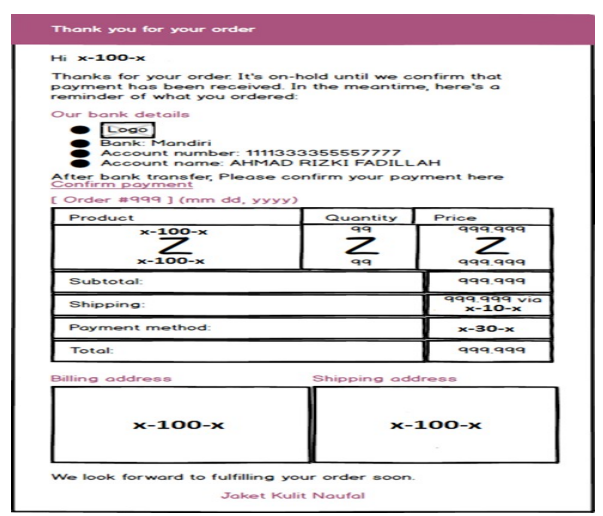

Gambar 16. Sistem Usulan Keluaran Email Order Customer

\section{KESIMPULAN}

Hasil dari kesimpulan penelitian ini yaitu:

a. Dengan dibuatkannya website e-commerce pemasaran pada toko Jaket Kulit Naufal lebih optimal dibandingkan sistem lama yang masih manual sehingga dapat mempermudah proses transaksi pembelian produk.

b. Dengan dibuatkannya website e-commerce ini diharapkan dapat memperluas area ruang lingkup toko dalam memaksimalkan serta meningkatkan pelayanan penjualan di banyak wilayah baik wilayah dalam kota maupun wilayah luar kota.

c. Website e-commerce ini menyajikan laporanlaporan diantaranya laporan pemesanan, laporan penjualan, laporan pembayaran, laporan pengiriman, laporan best seller dan laporan stock. Laporan tersebut ditujukan kepada pemilik toko sebagai bahan pertimbangan dalam perbaikan pelayanannya dan pengambilan keputusan.

d. Dengan adanya website e-commerce ini proses bisnis pada toko Jaket Kulit Naufal lebih mudah.

\section{DAFTAR PUSTAKA}

[1] Setiawan Iwan. Wirausaha Masa Depan, Kekuatan Dunia Baru Menuju Kemakmuran Hijau. Jakarta: Penebar Swadaya, Anggota lkapi., 2012

[2] Aryanto, A, Tjendrowasono, I, T. Pembangunan Sistem Penjualan Online Pada Toko Indah Jaya Furniture Surakarta, 2012, 1-7.

[3] Alfiah, F., Harahap, E. P., Pahad, B. A., Azhari, I. A., \& Saputra, R. S., Analisis Peran Teknologi Internet Sebagai Media Transaksi Electronic Commerce Untuk Meningkatkan, 2015, 6-8.

[4] Sri, R., Rejeki, A., Utomo, A. P., \& Susanti, S. Perancangan Sistem Penjualan pada Distro Smith Berbasis E-Commerce, 2015 , 150-159.
[5] Yudhanto Yudha. Technology Information Business Start-up. Jakarta: PT Elex Media Komputindo., 2019

[6] Sovia Elinawati, Abulwafa Muhammad, S. A. Rancang Bangun CMS Dengan Studi Kasus Electronic Bisnis Pada Toko Gorden Alya. Jurnal KomTekInfo Fakultas Ilmu Komputer, 2015, 79-90.

[7] Nawaningtyas, N., Waluyo, A., Munawar, A., \& Setyawansyah, S. Penerapan Desain Interior Dengan Menggunakan Sistem Market Jasa Dekorasi Dan Wordpress. Proceeding of The 4th Informatics Conference, 2017, 1-4.

[8] Fathurrahman. Pembuatan Website Praktis dan Mudah dengan Menggunakan Webbly. Jakarta: PT Elex Media Komputindo., 2014

[9] Enrico Oley, Dr.Eng Steven R. Sentinuwo, ST., MTI, Alicia A.E. Sinsuw, ST., M. Sistem Pemesanan Makanan Dan Minuman Berbasis Online. Conference on Lasers and Electro-Optics and 2006 5(5)., 2016 https://doi.org/10.1109/CLEO.2006.4628523

[10] Evi \& Gede. Langkah - langkah Desain Proyek dengan Menggunakan UML. Yogyakarta: CV. Andi Offset., 2012 